\title{
Classification of a moderately oxygen-tolerant isolate from baby faeces as Bifidobacterium thermophilum
}

\author{
Ueli von Ah ${ }^{1}$, Valeria Mozzetti ${ }^{1}$, Christophe Lacroix ${ }^{1}$, Ehab E Kheadr ${ }^{2}$, \\ Ismaïl Fliss ${ }^{2}$ and Leo Meile*1
}

Address: ${ }^{1}$ Institute for Food Science and Nutrition, Laboratory of Food Biotechnology, Swiss Federal Institute of Technology, ETH Zentrum, Zürich, Switzerland and 2Dairy Research Group STELA, Pavillon Paul Comtois, Université Laval, Québec, Canada

Email: Ueli von Ah - ueli.vonah@gmail.com; Valeria Mozzetti - valeria.mozzetti@ilw.agrl.ethz.ch;

Christophe Lacroix - christophe.lacroix@ilw.agrl.ethz.ch; Ehab E Kheadr - ehab.kheadr@aln.ulaval.ca; Ismaïl Fliss - ismail.fliss@aln.ulaval.ca; Leo Meile* - leo.meile@ilw.agrl.ethz.ch

* Corresponding author

Published: 21 August 2007

BMC Microbiology 2007, 7:79 doi:10.1/86/147|-2180-7-79
Received: 5 October 2006

Accepted: 2I August 2007

This article is available from: http://www.biomedcentral.com/I47I-2180/7/79

(C) 2007 von Ah et al; licensee BioMed Central Ltd.

This is an Open Access article distributed under the terms of the Creative Commons Attribution License (http://creativecommons.org/licenses/by/2.0), which permits unrestricted use, distribution, and reproduction in any medium, provided the original work is properly cited.

\begin{abstract}
Background: Bifidobacteria are found at varying prevalence in human microbiota and seem to play an important role in the human gastrointestinal tract (GIT). Bifidobacteria are highly adapted to the human GIT which is reflected in the genome sequence of a Bifidobacterim longum isolate. The competitiveness against other bacteria is not fully understood yet but may be related to the production of antimicrobial compounds such as bacteriocins. In a previous study, 34 Bifidobacterium isolates have been isolated from baby faeces among which six showed proteinaceous antilisterial activity against Listeria monocytogenes. In this study, one of these isolates, RBL67, was further identified and characterized.

Results: Bifidobacterium isolate RBL67 was classified and characterized using a polyphasic approach. RBL67 was classified as Bifidobacterium thermophilum based on phenotypic and DNA-DNA hybridization characteristics, although $16 \mathrm{~S}$ rDNA analyses and partial groEL sequences showed higher homology with $B$. thermacidophilum subsp. porcinum and B. thermacidophilum subsp. thermacidophilum, respectively. RBL67 was moderately oxygen-tolerant and was able to grow at pH 4 and at a temperature of $47^{\circ} \mathrm{C}$.

Conclusion: In order to assign RBL67 to a species, a polyphasic approach was used. This resulted in the classification of RBL67 as a Bifidobacterium thermophilum strain. To our knowledge, this is the first report about $B$. thermophilum isolated from baby faeces since the $B$. thermophilum strains were related to ruminants and swine faeces before. $B$. thermophilum was previously only isolated from animal sources and was therefore suggested to be used as differential species between animal and human contamination. Our findings may disapprove this suggestion and further studies are now conducted to determine whether B. thermophilum is distributed broader in human faeces. Furthermore, the postulated differentiation between human and animal strains by growth above $45^{\circ} \mathrm{C}$ is no longer valid since $B$. thermophilum is able to grow at $47^{\circ} \mathrm{C}$. In our study, $16 \mathrm{~S} \mathrm{rDNA}$ and partial groEL sequence analysis were not able to clearly assign RBL67 to a species and were contradictory. Our study suggests that partial groEL sequences may not be reliable as a single tool for species differentiation.
\end{abstract}




\section{Background}

Since Tissier discovered the Bifidobacterium spp. in 1899 [1], over 30 species have been isolated and identified [2] and the first genome sequence of a Bifidobacterium is now available [3]. Analyses of amplified partial 16S rDNA sequences assigned to uncultivated bifidobacteria suggest the existence of more new Bifidobacterium species[4,5]. Bifidobacteria are known to be heterofermentative anaerobic, Gram-positive bacteria which belong to the class of Actinobacteria [6] containing genomes with a high $\mathrm{G}+\mathrm{C}$ content. They mainly colonize the intestines of humans, other mammals and insects [7]. Some bifidobacteria have also been isolated from environmental sources such as sewage [8]. Bifidobacteria have been described as strictly anaerobic bacteria in the sense that they are not able to grow on agar-plates in the presence of air [7]. However, some Bifidobacterium strains were described which were at least partially aerotolerant in the presence of reducing agents in liquid media $[9,10]$. Genome analyses of Bifidobacterium longum suggests that both growth and survival under oxygen pressure are linked with the presence of a set of oxygen-scavenging NADH oxidases [3]. Strains of a novel species, Bifidobacterium psychraerophilum, were recently reported to be able to grow under air on the surface of solid agar-medium [11]. Based on heat-shock protein HSP60 encoding sequence homologies, this species clusters distinctly from aerotolerant species of the genera Scardovia, Aeriscardovia, Parascardovia and Gardnerella which were related or belonged to the genus Bifidobacterium before the recent reclassification $[11,12]$. For probiotic use of a particular Bifidobacterium strain, oxygen tolerance is an important characteristic for maintaining cell viability in end products.

The classification of Bifidobacterium species has most often been done in the past mainly by $16 \mathrm{~S}$ rDNA sequence homology analysis [13] and confirmed by an enzymatic assay of D-fructose-6-phosphate phosphoketolase [14] whose encoding gene $x f p$ is widespread among microorganisms and not unique to Bifidobacterium species [15]. These results were then substantiated by determinations of DNA-DNA relatedness [16] as well as physiological properties such as carbohydrate fermentation profiles in order to discriminate between single species of the genus Bifidobacterium. Recently, phylogenetic trees for bifidobacteria were constructed based on groEL genes encoding heat-shock protein HSP60 $[17,18]$, groES genes encoding chaperon [18] and $x f p$ encoding phosphoketolase $[19,20]$ as alternatives to 16S rDNA-based phylogenetic trees. These trends support the polyphasic approach for species identification as suggested several years ago [21]. The phylogenetic positions of bifidobacteria groEL (synonymly used with HSP60 encoding sequences) seem to generally agree with $16 \mathrm{~S}$ rDNA-based phylogeny, and in several studies, have been more discriminative than 16S rDNA sequences for species delineation [18]. In a previous study, 34 isolates of Bifidobacterium species from infant faeces have been described, six of which showed bacteriocin-like activity against Listeria monocytogenes which represents a rare property among bifidobacteria [22]. In this work, the taxonomic position of one of these isolates, strain RBL67, whose properties did not match with any of the so far described Bifidobacterium species, was determined using $16 \mathrm{~S}$ rDNA sequence homology, comparative groEL gene sequence analysis, DNA-DNA genome hybridizations and carbohydrate fermentation patterns. This study aimed to classify RBL67 due to its features which may be used industrially in the future and was not intended to for a complete phylogenetic analysis of Bifidobacterium sp.

\section{Results and discussion Phylogenetic position of Bifidobacterium sp. RBL67}

Because 16S rDNA sequences are the most widely used molecules in phylogenetic classification of bacteria, the 16 S rDNA fragment of strain RBL67 was amplified by PCR using the $\operatorname{lm} 3 / \operatorname{lm} 26$ primer pair (Table 1 ). The sequence of the resulting fragment (approx. $1.5 \mathrm{~kb}$ [Genbank:DQ340557]) showed the highest homologies to $16 \mathrm{~S}$ rDNA sequences of other bifidobacteria from the GenBank (Table 2) with the highest similarity, 99\%, to the sequence of Bifidobacterium thermacidophilum subsp. porcinum LMG21689 ${ }^{\mathrm{T}}$ [GenBank: AY148470], isolated by Zhu et al. [17], and $94 \%$ to that of the Bifidobacterium thermophilum type strain [GenBank: U10151] (Table 2). A phylogenetic tree was constructed from the 16S rDNA sequences using a consensus length of $1392 \mathrm{~kb}$. The tree shows clustering of RBL67 with the Bifidobacterium thermophilum/thermacidophilum/boum branch (Fig. 1), described as the "thermophilic group" by Zhu et al. [17].

There is insufficient discriminating power to clearly assign a $16 \mathrm{~S}$ rDNA to a species within the genus Bifidobacterium since similarity values for this gene can range from $93 \%$ to 99\% between species, as reported in other studies [23-25]. Therefore a polyphasic approach, as suggested by Van-

Table I: Oligonucleotides used in this study

\begin{tabular}{ll}
\hline Primer & Sequence (5'-3') \\
\hline Im3 & CGGGTGCTICCCACTTTCATG [42] \\
Im26 & GATTCTGGCTCAGGATGAACG [42] \\
$520 F$ & CAGGAGTGCCAGCAGCCGCGG [25] \\
$520 \mathrm{R}$ & ACCGCGGCTGCTGGC [25] \\
II00F & CAGGAGCAACGAGCGCAACCC [25] \\
II00R & AGGGTTGCGCTCGTT [25] \\
H60F & GGNGAYGGNACNACNACNGCNACNG [34] \\
H60R & TCNCCRAANCCNGGNGCYTTNACNGC [34] \\
T7 & TAATACGACTCACTATAGG [Promega] \\
SP6 & ATTTAGGTGACACTATAG [Promega]
\end{tabular}


Table 2: I6S rDNA sequence homologies of Bifidobacterium sp. RBL67 with I6S rDNA sequences found in the GenBank

\begin{tabular}{|c|c|}
\hline Bifidobacterium sp. RBL67 [GenBank: DQ340557] compared with* & $\%$ Identity $\{$ Gaps\} \\
\hline Bifidobacterium thermacidophilum subsp. porcinum LMG $21689^{\top}$ complete sequence [GenBank: $\underline{A Y \mid 48470}$ ] & $99\{2\}$ \\
\hline Bifidobacterium boum JCMI2IIT I6S rDNA partial sequence [Genbank: $\underline{D 86190}$ ] & $97\{2\}$ \\
\hline Bifidobacterium sp. group I-3 I6S ribosomal RNA gene, partial sequence [GenBank: AF32I295] & $97\{5\}$ \\
\hline B. thermacidophilum subsp. thermacidophilum LMG21395' I6S rDNA complete sequence [GenBank: $\underline{\mathrm{ABO} 16246}$ ] & $96\{12\}$ \\
\hline Bifidobacterium saeculare DSM6533 I6S rDNA partial sequence [GenBank: D89330] & $95\{6\}$ \\
\hline Bifidobacterium subtile JCM 7109' I6S rDNA partial sequence [GenBank: D89329] & $95\{6\}$ \\
\hline Bifidobacterium thermophilum ATCC $25525^{\top}$ I $6 \mathrm{~S}$ rDNA partial sequence [GenBank: UI0I5I] & $94\{8\}$ \\
\hline
\end{tabular}

*Accession numbers in brackets []

damme et al. [21], was used in this study to identify the unknown strain RBL67 at species level.

\section{Comparative analysis of groEL gene sequences}

The next step of the classification process was to compare the partial groEL gene sequences ( $0.59 \mathrm{~kb}$ in size) of Bifidobacterium RBL67 [GenBank: DQ340558], B. thermacidophilum subsp. thermacidophilum LMG21395 ${ }^{\mathrm{T}}$ [GenBank:
AY004276] (referred as B. thermacidophilum in Fig. 1 and Fig. 2) and B. thermacidophilum subsp. porcinum LMG21689' [GenBank: AY166561] with those of other bifidobacteria from the GenBank. Based on a consensus length of $0.59 \mathrm{~kb}$, a phylogenetic tree was constructed (Fig. 2) and rooted with Bacillus subtilis W168 [GenBank: M81132]. The tree shows common clustering of strain RBL67 with the Bifidobacterium thermophilum/thermacido-

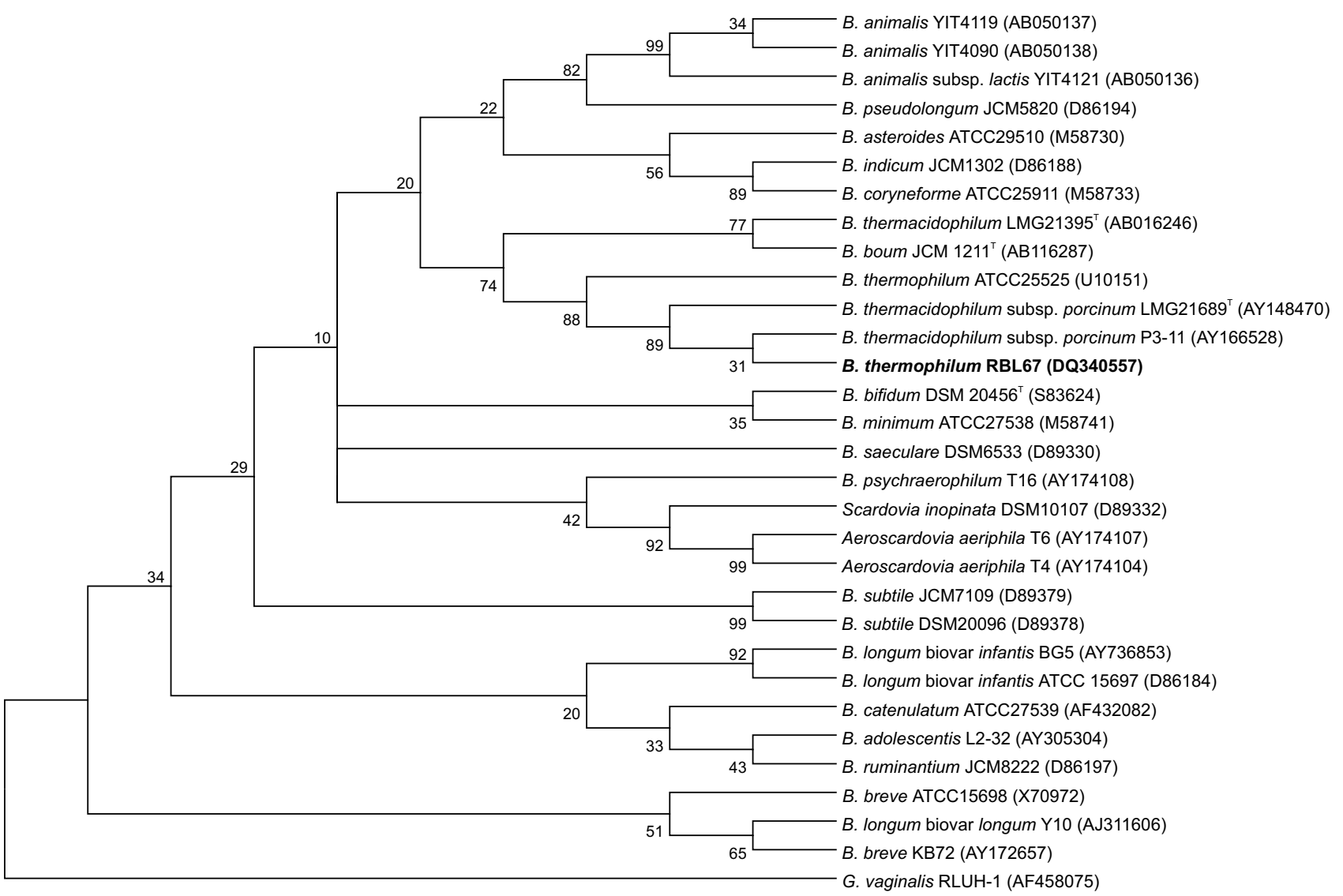

Figure I

Phylogenetic tree based on $16 \mathrm{~S}$ rDNA sequences. The tree was rooted with Gardnerella vaginalis RLUH-I and constructed by using the Neighbour-joining method with Jukes-Cantor parameter and a bootstrap value of 1000 . The number at each branch point represents percentage bootstrap support. Accession numbers in brackets. 
philum/boum branch, which substantiates the 16S rDNA comparisons presented in Fig. 1. According to the 16S rDNA tree, strain RBL67 splits off earlier on the branch and is closer related to $B$. thermophilum (Fig. 1 [GenBank: $\underline{10151}$ ]) whereas using partial groEL sequences, strain RBL67 is on the same branch as B. thermacidophilum (Fig. 2 [GenBank: AY004276]). The comparison of $16 \mathrm{~S}$ rDNA sequences and partial groEL sequences showed a discrepancy between the classification of strain RBL67 based on those methods. By comparing the partial groEL gene sequences, Bifidobacterium RBL67 is more closely related to $B$. thermacidophilum subsp. thermacidophilum LMG $21395^{\mathrm{T}}$ (98.25\% similarity) than to B. thermacidophilum subsp. porcinum LMG21689 $(97.06 \%$, Table 3) whereas based on 16S rDNA sequences strain RBL67 is closer related to $B$. thermacidophilum subsp. porcinum LMG21689 $(99 \%$, Table 2) than to B. thermacidophilum subsp. thermacidophilum LMG21395 ${ }^{\mathrm{T}}$ (96\%). According to the definition of Zhu et al. [17] a similarity of 96.5-100\% and $95.5-97 \%$ is required for intraspecies and inter-subspecies differentiation by partial groEL sequences, respectively. By applying this definition to partial groEL gene sequencing data (Table 3), Bifidobacterium RBL67 could belong to the species thermacidophilum or it could be a subspecies of $B$. thermophilum DSM20210 $(95.65 \%$ similarity), which is contradictory. Clearly sequencing analysis of partial groEL could not provide enough evidence to confirm the phylogenetic classification of Bifidobacterium isolate RBL67.

\section{DNA-DNA hybridization and G+C-content}

For the final classification of Bifidobacterium RBL67, DNADNA hybridization was performed. The results (Table 4) confirmed that the partial groEL gene sequence was not sufficient to differentiate between species. According to the limit of $70 \%$ similarity required for species identification [26], only Bifidobacterium boum DSM $20432^{\mathrm{T}}$ could be defined as a different species by DNA-DNA hybridization. B. thermacidophilum subsp. thermacidophilum LMG21395 was on the limit of this definition; its classification as a new species was justified by data from both DNA-DNA hybridization and phylogenetic data reported by Dong et al. [8]. However, our DNA-DNA hybridizations provide evidence that $B$. thermacidophilum subsp. porcinum LMG21689T belongs to $B$. thermophilum, showing $82.25 \%$ homology to B. thermophilum DSM20210 ${ }^{\mathrm{T}}$ (Table 4). Bifi- dobacterium RBL67 showed $86.25 \%$ homology with $B$. thermophilum DSM20210 $10^{\mathrm{T}}$ and could also not be discriminated as a new species. Bifidobacterium RBL67 showed even less similarity to $B$. thermacidophilum subsp. thermacidophilum LMG21395' and B. thermacidophilum subsp. porcinum LMG21689T than to $B$. thermophilum DSM20210 ${ }^{\mathrm{T}}$ (Table 4). Furthermore the homologies between Bifidobacterium RBL67 and both B. thermacidophilum strains were similar $\left(77.9 \%\right.$ for LMG $21395^{\mathrm{T}}$ and $77.2 \%$ for LMG21689T) while the homology between $B$. thermacidophilum subsp. thermacidophilum LMG21395'T and $B$. thermacidophilum subsp. porcinum LMG21689 $9^{\mathrm{T}}$ was only $71.9 \%$. The result reported by Dong et al. [8] from DNA-DNA hybridization, $58.9 \%$ similarity between $B$. thermacidophilum subsp. thermacidophilum LMG21395 and B. thermophilum DSM20210 ${ }^{\mathrm{T}}$, was not confirmed in this study. This might be due to different methods of DNA isolation, DNA-DNA hybridization or interpretation of the data.

Based on the data by DNA-DNA hybridization, which is still the strongest method for bacterial species differentiation, we classified strain RBL67 as Bifidobacterium thermophilum.

The G+C content of DNA from Bifidobacterium RBL67 was $59.7 \mathrm{~mol}-\%$ as determined by DSMZ Germany. This compared well with the $\mathrm{G}+\mathrm{C}$ determination of $B$. thermophilum DSM20210 ${ }^{\mathrm{T}}, 60 \mathrm{~mol}-\%$, but differed from that of $B$. thermacidophilum subsp. thermacidophilum LMG21395 $\mathrm{T}$ and $B$. thermacidophilum subsp. porcinum LMG21689', which were 57.7 and $61.5 \mathrm{~mol}-\% \mathrm{G}+\mathrm{C}$, respectively.

\section{Physiological properties of Bifidobacterium sp. RBL67}

Cells of Bifidobacterium RBL67 grew well on MRS-C agar incubated anaerobically at $37^{\circ} \mathrm{C}$ overnight and on RBagar at $40^{\circ} \mathrm{C}$ in $48 \mathrm{~h}$. They were non-motile, irregularly shaped rods and formed pairs when growing on plates (Fig. 3a). On RB-agar, they formed yellow colonies with a diameter of $1 \mathrm{~mm}$. When growing in liquid culture, agglomeration of cells occurred (Fig. 3b). This agglomeration was $\mathrm{pH}$ dependent: the lower the $\mathrm{pH}$, the greater the agglomeration of cells. The formation of agglomerates was inhibited by $\mathrm{pH}$ control at $\mathrm{pH} 7$ (data not shown). In contrast to $B$. thermacidophilum subsp. thermacidophilum LMG21395', aggregated cell clumps of Bifidobacterium

Table 3: Partial groEL sequence of Bifidobacterium sp. RBL67 compared with closely related Bifidobacterium species

\begin{tabular}{ll}
\hline Bifidobacterium sp. RBL67 groEL [GenBank: DQ340558] gene sequence compared with: & \% Similarity \\
\hline B. thermacidophilum subsp. thermacidophilum LMG $21395^{\top}$ [GenBank: AY004276] & $98.25 \%$ \\
B. thermacidophilum subsp. porcinum LMG $21689^{\top}[$ GenBank: AY16656I] & $97.06 \%$ \\
B. thermophilum DSM $20210^{\top}[$ GenBank: AF240567] & $95.65 \%$ \\
B. boum DSM $20432^{\top}$ [GenBank: AY004285] & $93.58 \%$
\end{tabular}




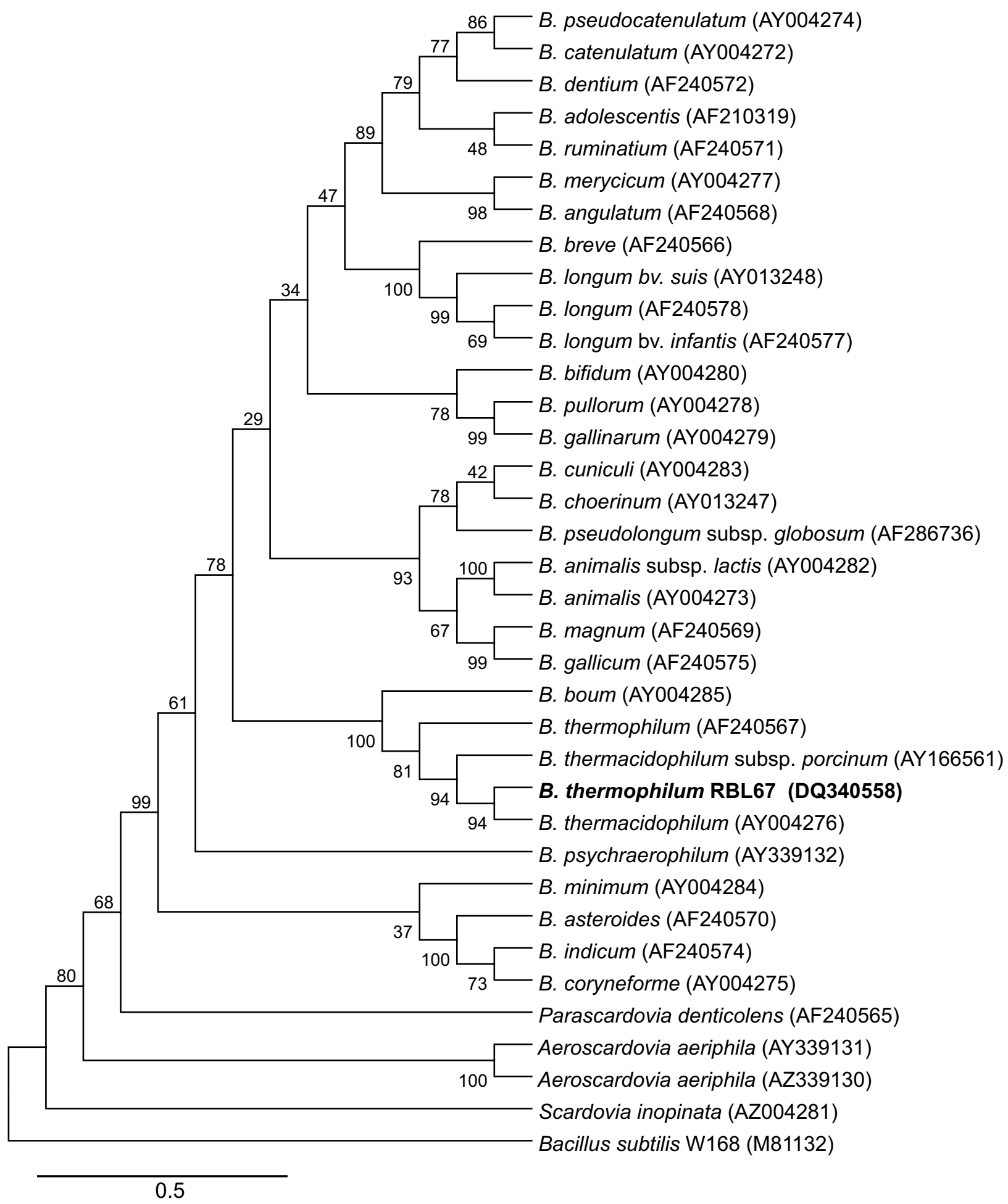

\section{Figure 2}

Phylogenetic tree based on fragments of the partial groEL gene DNA sequences rooted with Bacillus subtilis WI68. The tree was constructed using the neighbour-joining method with Jukes-Cantor parameter and bootstrap values calculated from 1000 trees (represented as percentages at each branch-point). Accession numbers in brackets. 
Table 4: Similarity in percent of the DNA-DNA hybridizations of Bifidobacterium RBL67, B. thermacidophilum subsp. porcinum LMG2 $1689^{\top}$ and $B$. thermophilum DSM20 $10^{\top}$ with closely related strains

\begin{tabular}{|c|c|c|c|}
\hline & Bifidobacterium sp. RBL67 & $\begin{array}{l}\text { B. thermacidophilum subsp. porcinum } \\
\text { LMG21689' }\end{array}$ & $\begin{array}{l}\text { B. thermophilum } \\
\text { DSM20210 }\end{array}$ \\
\hline Bifidobacterium sp. RBL67 & $100 \%$ & n.d. & n.d. \\
\hline B. thermacidophilum subsp. thermacidophilum LMG $21395^{\top}$ & $78 \%$ & $72 \%$ & $71 \%$ \\
\hline B. thermacidophilum subsp. porcinum LMG2 I689' & $77 \%$ & $100 \%$ & $82 \%$ \\
\hline B. thermophilum DSM20210 $0^{\top}$ & $86 \%$ & n. d. & $100 \%$ \\
\hline B. boum DSM $20432^{\top}$ & $48 \%$ & n. d. & n. d. \\
\hline
\end{tabular}

\section{n. d.: not determined}

RBL67 were not easily dispersed again, even after extended mixing.

Bifidobacterium RBL67 was moderately oxygen tolerant; therefore it was not necessary to perform dilutions and inoculations anaerobically. However, the strain did not grow on agar plates under aerobic conditions after 7 days. No selected gas atmosphere was necessary to grow the strain in liquid culture. While sparkling the liquid media with oxygen-free nitrogen or carbon dioxide, Bifidobacterium RBL67 ceased to grow. To determine the level of oxygen tolerance, anaerobic media were purged with oxygen as described by Meile et al. [10]. Fig. 4 shows the growth curves for Bifidobacterium sp. RBL67 at different levels of oxygen in reduced medium. At 2.5\% oxygen in the bottle growth of this strain was maintained, showing its elevated tolerance to oxygen. Even at $12.5 \%$ oxygen, the OD still increased fivefold during incubation for $12 \mathrm{~h}$. B. thermacidophilum subsp. thermacidophilum LMG21395' and $B$. thermacidophilum subsp. porcinum LMG21689 showed similar growth curves to strain RBL67 under oxidative stress, but seemed to grow slightly better at $12.5 \%$ oxygen after $10 \mathrm{~h}$ of fermentation (data not shown). Nonetheless, all the strains tested were less oxygen tolerant than $B$. animalis subsp. lactis, which was shown to tolerate $50 \mathrm{ml}$ of oxygen in comparable reduced medium [10].

Table 5 shows a summary of the fermentation profiles and growth extremes of Bifidobacterium RBL67, RBL68, RBL70, $B$. thermacidophilum subsp. thermacidophilum LMG21395T, B. thermacidophilum subsp. porcinum LMG21689T, B. animalis subsp. lactis DSM $10140^{\mathrm{T}}$ and B. thermophilum DSM20210 ${ }^{\mathrm{T}}$. For the determination of the growth limits for $\mathrm{pH}$ and temperature a limit of $\mathrm{OD}_{600} \geq 0.4$ after 7 days incubation was set. Bifidobacterium RBL67 was found to grow in a very large $\mathrm{pH}$ and temperature range (Table 5). Its maximum growth temperature $\left(47^{\circ} \mathrm{C}\right)$ was very close to that of $B$. thermophilum DSM20210 ${ }^{\mathrm{T}}$, although the later grew to a higher OD (data not shown). B. thermacidophilum subsp. thermacidophilum LMG $21395^{\mathrm{T}}$ was the only strain in this study that grew at $49^{\circ} \mathrm{C}$ which confirmed the growth characteristics described by Dong et al. [8].

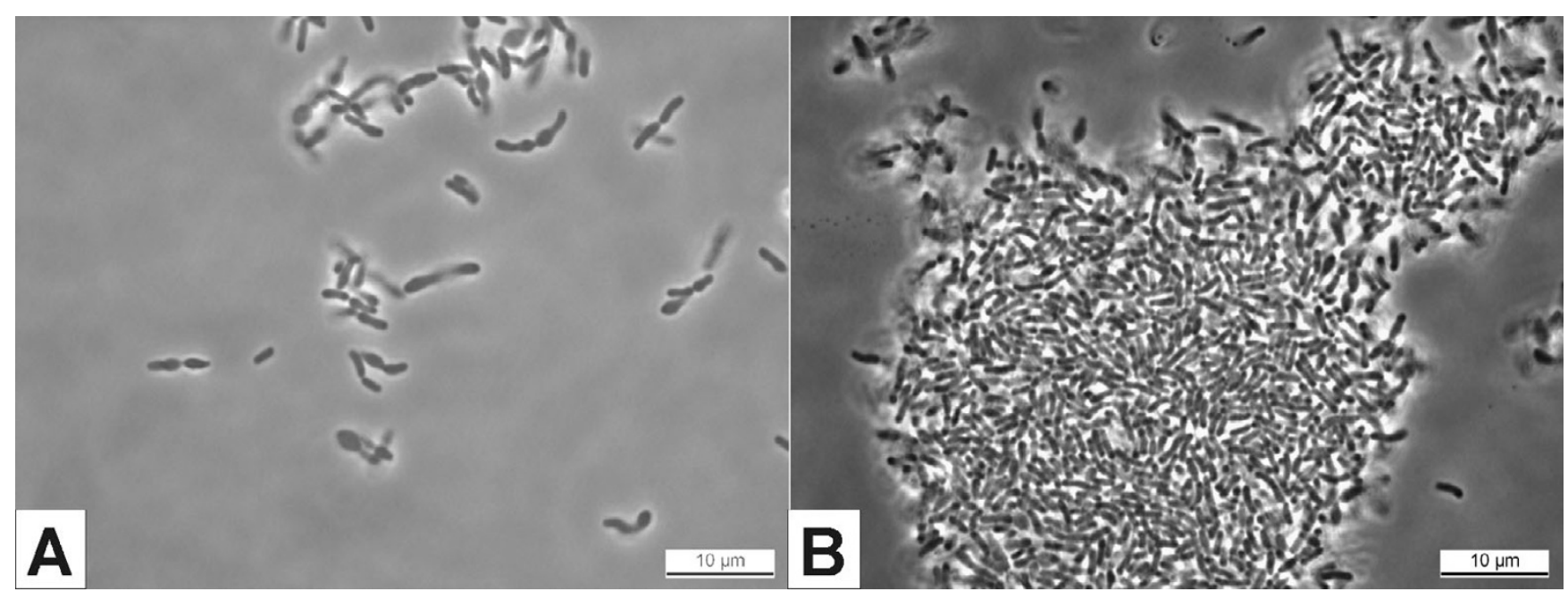

Figure 3

A: Microscopic picture of Bifidobacterium RBL67 grown on MRS-C agar overnight. White bar indicates $10 \mu \mathrm{m}$. B: Microscopic picture of a small agglomerated clump of Bifidobacterium RBL67 cells in MRS-C liquid culture after $24 \mathrm{~h}$ growth at $37^{\circ} \mathrm{C}$. White bar indicates $10 \mu \mathrm{m}$. 


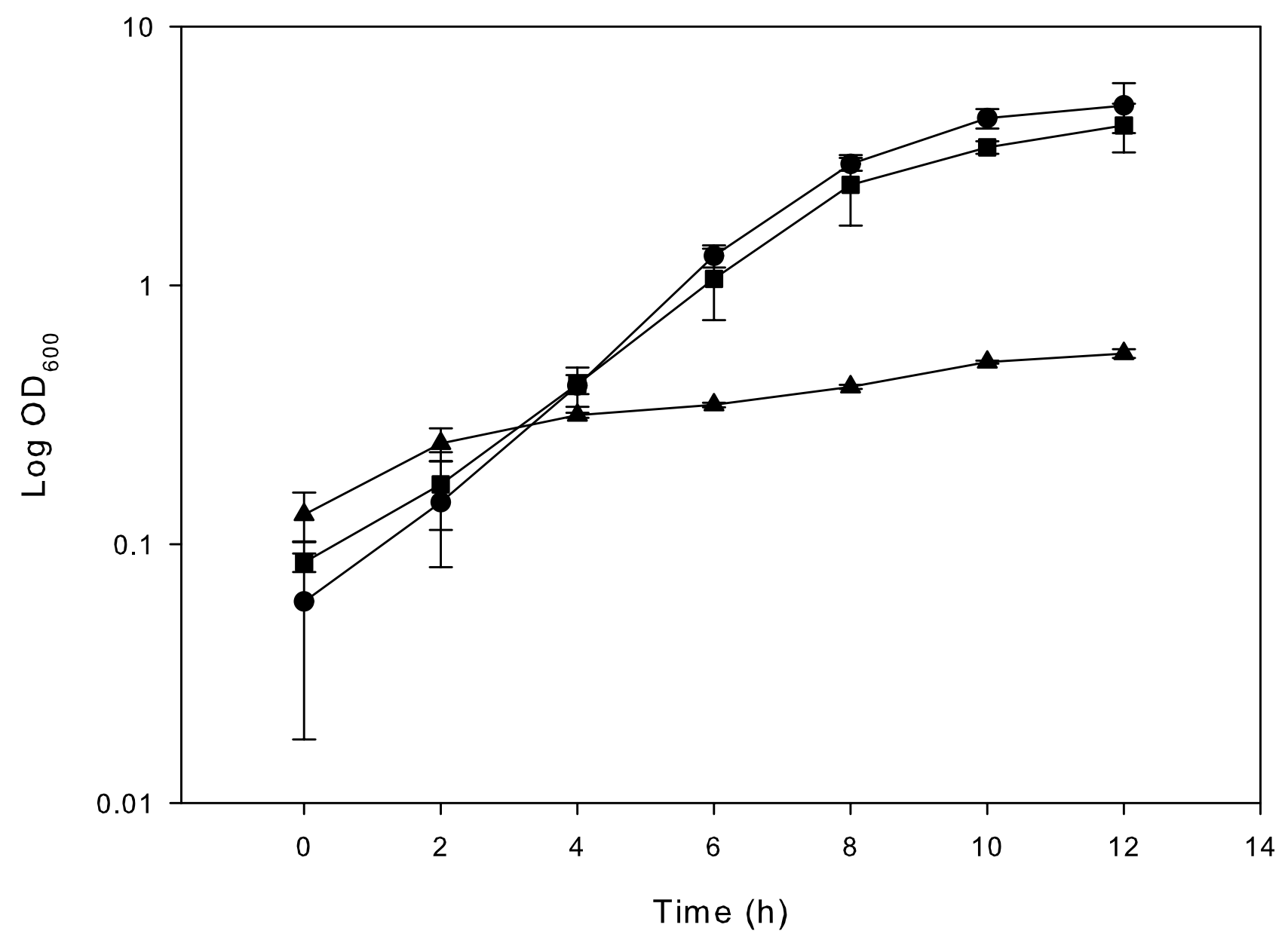

\section{Figure 4}

Growth of Bifidobacterium RBL67 under different oxygen concentrations in MRS-C at $37^{\circ} \mathrm{C}$. Points are mean of three replicates. Growth under anaerobic conditions; Growth with $2.5 \%$ oxygen; $\Delta$ Growth with $12.5 \%$ oxygen.

As for a lower pH limit, RBL67 and RBL70 were the only strains still growing at $\mathrm{pH} 4$ under the growth conditions of the study. B. thermacidophilum subsp. thermacidophilum LMG21395 ${ }^{\mathrm{T}}$ did not grow at this $\mathrm{pH}$, which was reported by Dong et al. [8]. The upper $\mathrm{pH}$ limit for growth was not determined, but all tested cultures still grew very well at $\mathrm{pH}$ 8. The molar ratio of acetate to lactate from glucose for Bifidobacterium RBL67 was determined as 5.91 to 1 in MRS-C medium at $37^{\circ} \mathrm{C}$ under anaerobic conditions.

\section{Conclusion}

In order to classify the Bifidobacterium isolate RBL67 at species level, we used a polyphasic approach since phylogenetic trees based on partial groEL gene (as used by Ventura et al. [18] and Dong et al. [8]) and 16S rDNA sequences generated similar but not identical results for species classification. Berthoud et al. [20] reported similar difficulties when studying the "thermophilic group", which could not be differentiated at the species level by $x f p$ gene sequencing. They proposed the use of $16 \mathrm{~S}$ rDNA sequencing, as an additional method for species differentiation. However, our DNA-DNA hybridization data (Table 4) revealed a very close relationship between $B$. thermophilum species and B. thermacidophilum species and questioned the current classification of $B$. thermacidophilum as a discrete species. Our hybridization data were substantiated by phylogenetic data, molecular characterization and physiological properties and allowed the classification of strain RBL67 into the species Bifidobacterium thermophilum. In contrast with a previous report [8], among our tested strains (Table 4 ) only B. boum could be clearly classified as a species different from $B$. ther- 
Table 5: Phenotypic characteristics of the tested Bifidobacterium species: 67:Bifidobacterium sp. RBL67; 68: Bifidobacterium sp. RBL68; 70:Bifidobacterium sp. RBL70; 21689 :B. thermacidophilum subsp.porcinum LMG2 1689'; 21395: B. thermacidophilum subsp.thermacidophilum LMG2 1395'; 20210: B. thermophilum DSM20210'; 10140: B. animalis subsp. lactis DSM I0I40'

\begin{tabular}{|c|c|c|c|c|c|c|c|}
\hline & 67 & 68 & 70 & 21689 & 21395 & 20210 & 10140 \\
\hline L-arabinose & - & - & - & - & + & - & + \\
\hline D-ribose & - & - & - & $\mathrm{D}$ & - & - & + \\
\hline D-galactose & $\mathrm{D}$ & + & $\mathrm{D}$ & + & + & + & + \\
\hline D-fructose & + & + & + & + & - & + & $\mathrm{D}$ \\
\hline D-mannose & - & - & - & - & - & - & $\mathrm{D}$ \\
\hline Methyl-AD-mannopyranoside & $\mathrm{D}$ & - & - & - & - & $\mathrm{D}$ & - \\
\hline Methyl-AD-glucopyranoside & + & $\mathrm{D}$ & - & + & + & + & + \\
\hline Amygdalin & - & - & - & - & $\mathrm{D}$ & + & + \\
\hline Arbutin & $\mathrm{D}$ & - & - & $\mathrm{D}$ & $\mathrm{D}$ & + & - \\
\hline Esculin ferric citrate & + & $\mathrm{D}$ & - & + & $\mathrm{D}$ & + & + \\
\hline Salicin & - & - & - & $\mathrm{D}$ & $\mathrm{D}$ & + & + \\
\hline D-lactose (bovine) & - & - & - & + & - & w & + \\
\hline D-trehalose & - & - & $\mathrm{D}$ & w & - & $\mathrm{D}$ & - \\
\hline Inulin & w & $\mathrm{D}$ & w & - & - & $\mathrm{D}$ & - \\
\hline Gentiobiose & - & - & - & - & - & + & $\mathrm{D}$ \\
\hline D-melezitose & - & - & $\mathrm{D}$ & - & - & $\mathrm{D}$ & - \\
\hline Minimum growth temp. $\left({ }^{\circ} \mathrm{C}\right)$ & $\leq 25$ & $\leq 25$ & n. d. & $\leq 25$ & $\leq 25$ & $\leq 25$ & $\leq 25$ \\
\hline Maximum growth temp. $\left({ }^{\circ} \mathrm{C}\right)$ & 47 & 47 & 47 & 47 & 49 & 47 & 46 \\
\hline Minimum growth $\mathrm{pH}$ & $\leq 4$ & $\leq 4.5$ & $\leq 4$ & $\leq 4.5$ & $\leq 4.5$ & $\leq 4.2$ & $\leq 4.5$ \\
\hline DNA G+C content (mol- $\%)$ & 59.7 & n. d. & n. d. & 61.5 & 57.7 & 60 & 61.9 \\
\hline
\end{tabular}

+, positive reaction; -, negative reaction; w, weak reaction; D, variable reaction $\rightarrow$ colour could not be assigned to either yellow or blue; $n$. d.: not determined

mophilum based on DNA-DNA hybridization. This finding suggests that partial groEL gene sequences may not be reliable as a single tool for Bifidobacterium species differentiation. However, more studies have to be done to confirm this suggestion.

As stated before, we did not intend to perform a complete phylogenetic analysis. However, as more data (16S rDNA sequences, groEL sequences) become available on strains closely related to $B$. thermophilum RBL67, a complete phylogenetic analysis could be performed which may lead to a new definition of the boum/thermophilum/thermacidophilum branch.

A very important finding of this study is that $B$. thermophilum could be isolated from human origin (baby faeces). In previous studies, B. thermophilum has been classified as an animal-related species mainly present in ruminant faeces $[27,28]$. Since it was previously possible to differentiate between animal and human bifidobacteria by species identification, it has been suggested that bifidobacteria should be used to discriminate between animal and human bacterial contamination in foods $[27,29]$. Because B. thermophilum RBL67 was isolated from baby faeces, it is likely that this species can not be used as animal contamination indicator. On the other hand, Gavini et al. [30] detected B. adolescentis, a species predominantly found in human, in cow dung, swine and rabbit faeces which restricts the number of bifidobacterial species that can be used for human faecal contamination detection.

Another discrimination tool between human and animal bifidobacteria strains was the temperature growth limit of $45^{\circ} \mathrm{C}$ for strains from human origin [7,31]. B. thermophilum strains are able to grow at $47^{\circ} \mathrm{C}$ and since they can also be found in human faeces [this study], the use of the temperature is not reliable anymore for the discrimination of the origin of bifidobacteria. However, since only a few species are able to grow above $45^{\circ} \mathrm{C}$, the assignment to a Bifidobacterium sp. can be narrowed. Further studies are now undergoing to determine whether $B$. thermophilum is more widespread within humans.

\section{Methods}

\section{Bacterial strains and routine growth conditions}

A list of strains used in this study is presented in Table 6. Strains were kept in their respective growth media (see below) supplemented with $30 \%(\mathrm{v} / \mathrm{v})$ glycerol at $-80^{\circ} \mathrm{C}$. Prior to use, all bifidobacteria were grown on RaffinoseBifidobacterium (RB)-agar plates [32], without sodium caseinate, supplemented with $1.5 \%$ (v/v) agar (Oxoid). After 5 sub cultivations they were transferred to MRS-C broth consisting of MRS with $0.1 \%(\mathrm{v} / \mathrm{v})$ Tween 80 (Biolife) and $0.05 \% \quad(\mathrm{w} / \mathrm{v})$ L-cysteine-hydrochloride (Sigma) or on MRS-C agar (MRS-C broth with $1.5 \%(\mathrm{w} / \mathrm{v}$ ) agar). Bifidobacterium bifidum DSM20456 ${ }^{\mathrm{T}}$ was cultivated 
only on MRS-C agar as it didn't grow on RB-agar. All strains were incubated anaerobically at $37^{\circ} \mathrm{C}$ overnight in MRS-C broth and agar, or at $40^{\circ} \mathrm{C}$ for $48 \mathrm{~h}$ on RB-agar.

\section{Growth under oxidative-, heat- and $\mathrm{pH}$-stress conditions}

Growth under conditions of oxidative stress was measured after a modified method described by Meile et al. [10]. Volumes of 0,10 and $50 \mathrm{ml}$ of pure oxygen were added to sterile serum flasks containing $400 \mathrm{ml}$ of MRS-C. The flasks were inoculated with $1 \%$ of an overnight culture of either B. longum subtype longum DSM 20219 , Bifidobacterium RBL67, B. thermacidophilum subsp. thermacidophilum LMG $21395^{\mathrm{T}}$ or $B$. thermacidophilum subsp. porcinum LMG $21689^{\mathrm{T}}$. The flasks were then incubated in a shaker at $160 \mathrm{rpm}$ and $37^{\circ} \mathrm{C}$ for $12 \mathrm{~h}$. Samples were taken every $2 \mathrm{~h}$ and treated for $3 \mathrm{~min}$ in a stomacher to remove clumps prior to measurements of the optical density at $600 \mathrm{~nm}$. Each growth curve was carried out twice.

The temperature and $\mathrm{pH}$ extremes of Bifidobacterium RBL67, RBL68 and RBL70, B. thermacidophilum subsp. thermacidophilum LMG $21395^{\mathrm{T}}$, B. thermacidophilum subsp. porcinum LMG $21689^{\mathrm{T}}$, B. animalis subsp. lactis DSM $10140^{\mathrm{T}}$ and $B$. thermophilum DSM 20210 ${ }^{\mathrm{T}}$ were determined as follows:

$25 \mathrm{ml}$ of MRS-C containing $2 \mathrm{mg} \mathrm{l}^{-1}$ resazurin as redox indicator were anaerobically inoculated with $1 \%$ of the tested bifidobacteria cultured overnight. The temperature range was evaluated by incubating the strains for 7 days at $12,25,46,47,48$ and $49^{\circ} \mathrm{C}$ with an initial $\mathrm{pH}$ of 7.0 . The $\mathrm{pH}$ range was determined using $\mathrm{pH} 4.0,4.5,5.0,5.5$ and
8.0 as initial $\mathrm{pH}$ for growth. Samples were incubated at $37^{\circ} \mathrm{C}$ for 7 days. Aliquots were taken daily, treated in a stomacher for $3 \mathrm{~min}$ and the OD was measured at 600 $\mathrm{nm}$. Each growth condition was measured twice. If a strain failed to reach $\mathrm{OD}_{600}$ of 0.4 after 7 days, it was declared as not growing under the tested conditions.

\section{Amplification and sequencing of I 6S rDNA}

Specific amplification of the $16 \mathrm{~S}$ rDNA of Bifidobacterium RBL67 and other bifidobacteria was done using a slightly modified PCR protocol established by Schürch [33] using the primer pair $\operatorname{lm} 3 / \operatorname{lm} 26$ (Table 1 ). The annealing temperature used was $62^{\circ} \mathrm{C}$ instead of $60^{\circ} \mathrm{C}$. After agarose gel electrophoresis the corresponding band for $16 \mathrm{~S}$ rDNA at the $1.5 \mathrm{~kb}$ position was cut out and purified using the GFX PCR purification kit (Amersham Biosciences). Sequencing of the PCR product was done by Microsynth GmbH using the primers 520F, 520R, 1100F and 1100R (Table 1). Sequence analysis and comparison was done using the GCG software package version 10 as described before [34]. Phylogenetic and molecular evolutionary analyses were conducted using MEGA version 3.1 [35]. The sequences were aligned with ClustalW (version 1.6) and the tree was calculated using the neighbour-joining method with Jukes-Cantor parameter and a bootstrap value of 1000 .

\section{Cloning and analysis of groEL sequences}

DNA cloning and sequencing of a partial heat shock groEL gene sequence from Bifidobacterium RBL67 were done using a modified method of Jian et al. [34]. The DNA template was extracted using the method of Leenhouts et al. [36]. To amplify part of a gene fragment with PCR, the fol-

Table 6: Strains used in this study

\begin{tabular}{|c|c|}
\hline Species & Strain \\
\hline Bifidobacterium thermacidophilum subsp. thermacidophilum & LMG $21395^{\top}$ \\
\hline Bifidobacterium thermacidophilum subsp. porcinum & LMG $21689 T$ \\
\hline Bifidobacterium adolescentis & DSM $20083^{\top}$ \\
\hline Bifidobacterium bifidum & DSM $20456^{\top}$ \\
\hline Bifidobacterium boum & DSM $20432^{\top}$ \\
\hline Bifidobacterium breve & DSM $20213^{\top}$ \\
\hline Bifidobacterium longum subtype infantis & DSM $20088^{\top}$ \\
\hline Bifidobacterium longum subtype longum & DSM $20219 \mathrm{~T}$ \\
\hline Bifidobacterium thermophilum & DSM $20210^{\top}$ \\
\hline Bifidobacterium longum subtype suis & DSM 202II \\
\hline Bifidobacterium animalis subsp. Lactis & DSM $10140^{\top}$ \\
\hline Bifidobacterium & RBL67* \\
\hline Bifidobacterium & RBL68* \\
\hline Bifidobacterium & RBL70* \\
\hline Escherichia coli & XLI-Blue \\
\hline
\end{tabular}

BCCM/LMG ${ }^{\mathrm{TM}}$ : Belgian co-ordinated collections of micro-organisms/Laboratorium voor Microbiology en microbiele Genetica, Ghent, Belgium

DSM: German Microorganism Collection, Braunschweig, Germany

*Isolated from baby faeces [22]; $\ddagger$ referred in Bullock et al. [4I] 
lowing reaction mixture ( $25 \mu \mathrm{l})$ was used: 3-30 ng DNA template measured at $260 \mathrm{~nm}$ with a Eppendorf-Biophotometer, $2.5 \mathrm{U}$ Taq polymerase (Euroclone), $0.1 \mathrm{mM}$ dNTP's (Amersham Biosciences), $1.5 \mathrm{mM} \mathrm{MgCl}_{2}, 2 \mu \mathrm{M}$ each of primer H60R and H6OF (Table 1) and $2.5 \mu \mathrm{l} 10 \times$ PCR buffer (Euroclone). The PCR reactions were carried out in a Biometra Tgradient Thermal Cycler using the following protocol: denaturation step $95^{\circ} \mathrm{C}$ for $5 \mathrm{~min}$ followed by 40 cycles of $94^{\circ} \mathrm{C}$ for $30 \mathrm{~s}, 50^{\circ} \mathrm{C}$ for $30 \mathrm{~s}$ and $72^{\circ} \mathrm{C}$ for $1 \mathrm{~min}$ at a heating rate of $1.5^{\circ} \mathrm{C} \mathrm{min}-1$. At the end, the temperature was maintained at $72^{\circ} \mathrm{C}$ for $10 \mathrm{~min}$. A $25-\mu \mathrm{l}$ aliquot of the reaction mixtures was mixed with $10 \mu$ l Orange G loading dye $(0.25 \%$ Orange G from Fluka in $30 \%$ glycerol) and subjected to electrophoresis on agarose $(0.8 \%)$ gels in $1 \times$ TAE buffer. DNA bands were visualized by $2.5 \mu \mathrm{g} \mathrm{ml}^{-1}$ ethidium bromide under UV light. Corresponding bands ( $0.59 \mathrm{~kb}$ in size) were then cut out and purified as described above.

Purified PCR fragments were ligated into the pGEM-T easy vector using the Promega PCR cloning kit. Ligation and cloning was performed according to the kit manual. Transformation of E. coli XL-1 blue cells was done using the electroporation method described by Sambrook and Russel [37]. Recombinant plasmids were extracted from transformed cells with the Promega Wizard Plus Midiprep DNA Purification System. Plasmid DNA (100 ng $\left.\mu^{-1}\right)$ carrying partial HSP60 encoding gene sequences from Bifidobacterium RBL67 or $B$. thermacidophilum subsp. thermacidophilum LMG $21395^{\mathrm{T}}$ was then sequenced by Microsynth GmbH and finally aligned to the corresponding sequences from bifidobacteria and Bacillus subtilis W168 (obtained from Genbank entries) using the CLUSTAL W software (version 1.6). Similarities were calculated and converted into a distance matrix with the Jukes-Cantor parameter and rooted with Bacillus subtilis W168 applying a bootstrap value of 1000 using the software MEGA version 3.1 [35].

\section{DNA-DNA hybridization}

Whole genome DNA-DNA hybridizations were carried out externally at DSMZ Germany. Hybridizations were performed with the genomes of Bifidobacterium RBL67, $B$. thermacidophilum subsp. thermacidophilum LMG21395 ${ }^{\mathrm{T}}$, $B$. thermacidophilum subsp. porcinum LMG21689 ${ }^{\mathrm{T}}, B$. thermophilum DSM 20210 and B. boum 20432 . Total DNA was isolated using a French pressure cell according to the method described by Cashion et al. [38], DNA-DNA hybridizations were carried out according to De Ley et al. [39] with modifications of Huss et al. [40] in $2 \times$ SSC and $10 \%$ formamide $(\mathrm{v} / \mathrm{v})$ at a temperature of $67^{\circ} \mathrm{C}$. The analyses were performed with a model Cary 100 Bio UV/VISspectrophotometer equipped with a Peltier-thermostated $6 \times 6$ multicell changer and a temperature controller with in situ temperature probe.

\section{Carbohydrate fermentation and acid analysis}

Carbohydrate fermentation of strain RBL67 was analyzed using API 50 CHL strips (Biomérieux). The tests were carried out in triplicates according to the manufacturer's instructions with a modification in culture preparation. Briefly, $2 \mathrm{ml}$ of an overnight culture in MRS-C broth were centrifuged $\left(14000 \mathrm{~g}, 5 \mathrm{~min}, 4^{\circ} \mathrm{C}\right)$. The pellet was then washed and resuspended in $1 \mathrm{ml}$ of autoclaved water. This suspension was then mixed with $5 \mathrm{ml} \mathrm{CHL50}$ medium (Biomérieux) and $0.1 \mathrm{ml}$ of this mixture was applied to each tube of the API test. The test strips were then incubated anaerobically for $72 \mathrm{~h}$ at $37^{\circ} \mathrm{C}$ and evaluated after 24,48 and $72 \mathrm{~h}$.

Molar ratio of acetic and lactic acid was determined using HPLC. $2 \mathrm{ml}$ of an overnight culture (16 h) of either Bifidobacterium RBL67, RBL68 or RBL70, B. thermacidophilum subsp. thermacidophilum LMG $21395^{\mathrm{T}}$ or B. thermacidophilum subsp. porcinum LMG $21689^{\mathrm{T}}$ were centrifuged $\left(14000 \mathrm{~g}, 5 \mathrm{~min}, 4^{\circ} \mathrm{C}\right)$. The supernatant was $10 \times$ diluted in HPLC-grade water and filtered $(0.45 \mu \mathrm{m})$ prior to HPLC analysis. This was carried out using an Aminex HPX-87H $(300 \times 7.8 \mathrm{~mm})$ column (Bio-Rad) in a Merck LaChrom HPLC system. Sulfuric acid ( $10 \mathrm{mM}$, Fluka) was used as mobile phase at a flow rate of $0.4 \mathrm{ml} \mathrm{min}^{-1}$. Sugars and acids were detected by a RI detector. Analyses were done in duplicate.

\section{Authors' contributions}

UVA did the first identification and characterization experiments, carried out the sequence alignments, prepared the DNA-DNA hybridizations, coordinated the study and drafted the manuscripts. VM did the molecular and phenotypic experiments, statistical analysis and participated in sequence alignment and DNA-DNA hybridization preparation. CL conceived the study and participated in the coordination of the study. LM participated in the coordination of the study and the sequence interpretation and helped in the draft of the manuscript. IF and EEK were responsible for the screening and isolation of bifidobacteria strains from baby faeces. All authors read and approved the final manuscript.

\section{Acknowledgements}

This study was supported by a grant from the Swiss National Foundation (Project $n^{\circ}$. 3100A0-102256). We thank Dr. G. Dasen for his support on some molecular techniques and Dr. Janice Sych for carefully reading the manuscript.

\section{References}

I. Tissier MH: La réaction chromophile d'Escherich et Bacterium Coli. CR Seances Soc Biol Fil I899, 5 I:943-945.

2. Klijn A, Mercenier A, Arigoni F: Lessons from the genomes of bifidobacteria. FEMS Microbiol Rev 2005, 29(3):49I-509.

3. Schell MA, Karmirantzou M, Snel B, Vilanova D, Berger B, Pessi G, Zwahlen M-C, Desiere F, Bork P, Delley M, et al.: The genome sequence of Bifidobacterium longum reflects its adaptation to 
the human gastrointestinal tract. Proc Natl Acad Sci USA 2002, 99(22): | 44222-I4427.

4. Ley RE, Peterson DA, Gordon Jl: Ecological and Evolutionary Forces Shaping Microbial Diversity in the Human Intestine. Cell 2006, I 24(4):837-848.

5. Satokari RM, Vaughan EE, Smidt H, Saarela M, Matto J, de Vos M: Molecular approaches for the detection and identification of bifidobacteria and lactobacilli in the human gastrointestinal tract. System Appl Microbiol 2003, 26:572-584.

6. Stackebrandt E, Rainey FA, Ward-Rainey NL: Proposal for a new hierarchic classification system, Actinobacteria classis nov. Int J Syst Bacteriol 1997, 47(2):479-49|

7. Biavati B, Mattarelli P: The family Bifidobacteriaceae. The prokaryotes: an evolving electronic resource for the microbiological community 3rd edition. 2005 [http://www.springer.com/west/home/life+sci/microbi ology?SGWID=4-10037-22-155417496-detailsPage=ppmme dialaboutThisBook]. New York: Springer

8. Dong X, Xin Y, Jian W, Liu X, Ling D: Bifidobacterium thermacidophilum sp. nov., isolated from an anaerobic digester. Int J Syst Bacteriol 2000, 50(I): I19-125.

9. Beerens H, Gavini F, Neut C: Effect of exposure to air on $\mathbf{8 4}$ strains of bifidobacteria. Anaerobe 2000, 6:65-67.

10. Meile L, Ludwig W, Rueger U, Gut C, Kaufmann P, Dasen G, Wenger S, Teuber M: Bifidobacterium lactis sp. nov, a moderately oxygen tolerant species isolated from fermented milk. System Appl Microbiol 1997, 20(1):57-64.

II. Simpson PJ, Ross RP, Fitzgerald GF, Stanton C: Bifidobacterium psychraerophilum sp. nov. and Aeriscardovia aeriphila gen. nov., sp. nov., isolated from a porcine caecum. Int J Syst Bacterio 2004, 54(2):40I-406.

12. Jian W, Dong X: Transfer of Bifidobacterium inopinatum and Bifidobacterium denticolens to Scardovia inopinata gen. nov., comb. nov., and Parascardovia denticolens gen. nov., comb. nov., respectively. Int / Syst Bacteriol 2002, 52(3):809-8/2.

13. Leblond-Bourget N, Philippe H, Mangin I, Decaris B: I6S rRNA and 165 to 235 internal transcribed spacer sequence analyses reveal inter- and intraspecific Bifidobacterium phylogeny. Int J Syst Bacteriol 1996, 46(I): I02-III.

14. Scardovi V, Trovatelli LD: The fructose-6-phosphate shunt as peculiar pattern of hexose degradation in the genus Bifidobacterium. Ann Microbiol Enzim 1965, 15:19-29.

15. Meile L, Rohr LM, Geissmann TA, Herensperger M, Teuber M: Characterization of the D-xylulose 5-phosphate/D-fructose 6phosphate phosphoketolase gene $(x \mathrm{fp})$ from Bifidobacterium lactis. J Bacteriol 200I, I 83(9):2929-2936.

16. Stackebrandt E, Goebel BM: Taxonomic note: a place for DNADNA reassociation and I6S rRNA sequence analysis in the present species definition in bacteriology. Int J Syst Bacteriol 1994, 44:846-849.

17. Zhu L, Li W, Dong X: Species identification of genus Bifidobacterium based on partial HSP60 gene sequences and proposa of Bifidobacterium thermacidophilum subsp. porcinum subsp. nov. Int J Syst Bacteriol 2003, 53(5):1619-1623.

18. Ventura M, Canchaya C, Zink R, Fitzgerald GF, van Sinderen D: Characterization of the gro EL and groES loci in Bifidobacterium breve UCC 2003: genetic, transcriptional, and phylogenetic analyses. Appl Environ Microbiol 2004, 70( I 0):6 197-6209.

19. Yin X, Chambers JR, Barlow K, Park AS, Wheatcroft R: The gene encoding xylulose-5-phosphate/fructose-6-phosphate phosphoketolase $(x f p)$ is conserved among Bifidobacterium species within a more variable region of the genome and both are useful for strain identification. FEMS Microbiol Lett 2005 , 246(2):25I-257.

20. Berthoud H, Chavagnat F, Haueter M, Casey MG: Comparison of partial gene sequences encoding a phosphoketolase for the identification of bifidobacteria. LMWT 2005, 38(I): I0I-I 05.

21. Vandamme P, Pot B, Gillis M, Vos Pd, Kersters K, Swings J: Polyphasic taxonomy, a consensus approach to bacterial systematics. Microbiol Rev 1996, 60:407-438.

22. Touré R, Kheadr E, Lacroix C, Moroni O, Fliss I: Production of antibacterial substances by bifidobacterial isolates from infant stool active against Listeria monocytogenes. J Appl Microbiol 2003, 95(5): 1058-1069.

23. Satokari R: Molecular identification and characterisation of bifidobacteria and lactobacilli in the human gastrointestinal tract. In PhD thesis Tietotie: Wageningen University; 2002.
24. Vaugien L, Prevots F, Roques C: Bifidobacteria identification based on I6S rRNA and pyruvate kinase partial gene sequence analysis. Anaerobe 2002, 8:34I-344.

25. Miyake T, Watanabe K, Watanabe T, Oyaizu H: Phylogenetic analysis of the genus Bifidobacterium and related genera based on I6S rDNA sequences. Microbiol Immunol I998, 42(10):66I-667.

26. Wayne LG, Brenner DJ, Colwell RR, Grimont PAD, Kandler O, Krichevsky MI, Moore LH, Moore WEC, Murray RGE, Stackebrandt $E$, et al:: Report of the ad hoc committee on reconciliation of approaches to bacterial systematics. Int J Syst Bacteriol 1987, 37:463-464

27. Delcenserie V, Bechoux N, Leonard T, China B, Daube G: Discrimination between Bifidobacterium species from human and animal origin by PCR-restriction fragment length polymorphism. J Food Prot 2004, 67(6): 1284-| 288.

28. Klein G, Pack A, Bonaparte C, Reuter G: Taxonomy and physiology of probiotic lactic acid bacteria. Int J Food Microbiol 1998 4 I(2): $103-125$

29. Beerens $\mathrm{H}$ : Bifidobacteria as indicators of faecal contamination in meat and meat products: detection, determination of origin and comparison with Escherichia coli . Int J Food Microbiol 1998, 40(3):203-207.

30. Gavini F, Delcenserie V, Kopeinig K, Pollinger S, Beerens H, Bonaparte C, Upmann M: Bifidobacterium species isolated from animal feces and from beef and pork meat. J Food Prot 2006, 69(4):87|-877.

31. Gavini F, Pourcher AM, Neut C, Monget D, Romond C, Oger C, lzard $D$ : Phenotypic differentiation of bifidobacteria of human and animal origins. Int J Syst Bacteriol I99 I, 4 I (4):548-557.

32. Hartemink R, Kok BJ, Weenk GH, Rombouts FM: Raffinose-Bifidobacterium (RB) agar, a new selective medium for bifidobacteria. J Microbiol Meth 1996, 27:33-43.

33. Schürch C: Development of a novel DNA transformation system for bifidobacteria. In PhD thesis Zurich: Swiss Federal Institute of Technology; 2002

34. Jian $W$, Zhu L, Dong $X$ : New approach to phylogenetic analysis of the genus Bifidobacterium based on partial HSP60 gene sequences. Int J Syst Bacteriol 200I, 5 I (5): I633-1638.

35. Kumar S, Tamura K, Nei M: MEGA3: Integrated software for Molecular Evolutionary Genetics Analysis and sequence alignment. Brief Bioinform 2004, 5: I50-163.

36. Leenhouts KJ, Kok J, Venema G: Campbell-like integration of heterologous plasmid DNA into the chromosome of Lactococcus lactis subsp. lactis. Appl Environ Microbiol I989, 55:394-400.

37. Sambrook J. Russel DW: Molecular Cloning: a laboratory manual. Volume I. 3rd edition. New York: Cold Spring Harbor Laboratory Press;; 2001.

38. Cashion P, Hodler-Franklin MA, McCully J, Franklin M: A rapid method for base ratio determination of bacterial DNA. Anal Biochem 1977, 8 I:46I-466.

39. Ley JD, Cattoir H, Reynaerts A: The quantitative measurement of DNA hybridization from renaturation rates. Eur J Biochem 1970, 12:133-142.

40. Huss VAR, Festl H, Schleifer KH: Studies on the spectrophotometric determination of DNA hybridization from renaturation rates. System Appl Microbiol 1983, 4:184-192.

4I. Bullock WO, Fernandez JM, Short JM: XLI-Blue: a high efficiency plasmid transforming recA Escherichia coli strain with betagalactoside selection. BioTechn 1987, 5:376-379.

42. Kaufmann P, Pfefferkorn A, Teuber M, Meile L: Identification and quantification of Bifidobacterium species isolated from food with genus-specific I6S rRNA-targeted probes by colony hybridization and PCR. Appl Environ Microbiol 1997, 63(4): $1268-1273$ 